\title{
ARTICLE \\ Day Time Sleepiness and Quality of Life Predicts Perceived Stress among Youth
}

\section{Sandeep Panchal ${ }^{*} \quad$ Monika Yadav $^{2}$}

1.Department of Psychology, Rajiv Gandhi University (A Central University), Doimukh, Itanagar, Arunachal Pradesh, India 2.Indira Gandhi University, Rewari, Haryana, India

\begin{tabular}{|c|c|}
\hline ARTICLE INFO & ABSTRACT \\
\hline Article history & \multirow{9}{*}{$\begin{array}{l}\text { The study examined the predictor of perceived stress among youth. The } \\
\text { variables used in the current study were day time sleepiness, quality of } \\
\text { life and perceived stress. The sample consists of } 150 \text { youth ( } 81 \text { Male \& } \\
69 \text { Female) with in the age range of } 18-24 \text { years. The Epworth Sleepiness } \\
\text { Scale (ESS), World Health Organization Quality of Life (WHO-BRIEF), } \\
\text { and Perceived Stress Scale (PSS) were used. The data were interpreted } \\
\text { after obtaining the descriptive statistics i.e. Mean and SD, Pearson's } \\
\text { Product Moment correlation and step wise multiple regression analysis. } \\
\text { The findings indicated that day time sleepiness and quality of life have a } \\
\text { significant positive relation with perceived stress among youth. The step } \\
\text { wise regression analysis found day time sleepiness and psychological } \\
\text { health related quality of life are the predictors of perceived stress. Both } \\
\text { the variable accounts for } 39 \% \text { of total variance in perceived stress among } \\
\text { youth. }\end{array}$} \\
\hline Received: 23 April 2021 & \\
\hline Accepted: 20 May 2021 & \\
\hline Published Online: 21 May 2021 & \\
\hline Keywords: & \\
\hline Day time sleepiness & \\
\hline Quality of life & \\
\hline Perceived stress & \\
\hline & \\
\hline
\end{tabular}

\section{Introduction}

Quality of life (QoL) can be understood in terms of individual's view about their position in life in connection with culture and value system. It is also concerns with the goals, perspectives, and standards ${ }^{[26]}$. In recent time, the study of QoL became very important to find out the effect of any illnesses/diseases and several interventions. However, very less importance has been observed in connection with QoL of university students at their educational phase, which is very high stressful time for students. Youth is a special population group in terms of fast changing period of life so their concerns and stressors differ from the other group of population. They may have various stressors, like academic pressure, financial issues, peer pressure problems and relationship issue. Because of many issues their quality of life may affect which lead to perceived stress among them.

Day time sleepiness is very normal for all but when it happens in an extreme way then it becomes problematic for the people. Excessive daytime sleepiness refers to the persistent sleepiness and has often a lack of energy, even during the day time after had adequate or prolonged night time sleep. Some of the research which focused on the sleep regulation and sleep related problems ${ }^{[1,2,3,4]}$. Individual perception of their position in life is known as quality

*Corresponding Author:

Sandeep Panchal,

Department of Psychology, Rajiv Gandhi University (A Central University), Doimukh, Itanagar, Arunachal Pradesh, India; Email: sandeep.panchal@rgu.ac.in 
of life it can be improved by adopting specific social skills like social expressivity, social control, by acquiring specific social skills youth can enhance their quality of life in an improved way ${ }^{[5]}$.

Earlier researches focused on general population not on the youth particularly so the current review is based on general finding. In a study that shows the relationship between stress and quality of life in a significant way, one of study indicated predictive roles of self-worth and family support in quality of life ${ }^{[6]}$. Study showed health-related quality of life is affected by the presence of chronic pain and mental disorders among university students ${ }^{[7]}$. In another study, investigation was conducted perceived stress in relation to sleep duration and found perceived stress was negatively related to sleep duration and positively related to poor sleep quality ${ }^{[8]}$. One of the study explored the perceived stress and health-related quality of life (HRQOL) among pharmacy students compared to non-pharmacy students. The study found that negative correlation between stress and mental HRQOL in Non-M-Pharm students ${ }^{[9]}$. In a study, it has examined the depression, anxiety, stress and quality of life among drug abusers in the normal population group. The results showed quality of life of normal people was higher than those who were addicted to opiates. Further, study also revealed anxiety; depression and stress were found negatively associated with quality of life ${ }^{[10]}$. In another research, it has been found that sleep quality index and quality of life significantly positively related with each other ${ }^{[11]}$. One of study examined perceived stress and quality of life among students and finding showed stress negatively affect quality of life among students ${ }^{[12]}$. In a systematic review it has been highlighted the negative association between stress and quality of life among university students ${ }^{[13]}$. Another study, which assessed the prevalence of stress and anxiety among college going students and finding reveal a high degree of depression, anxiety and stress among students ${ }^{[14]}$. Researcher investigated the prevalence and its correlation between stress and poor sleep quality among students who study medical. The study showed a significant relationship between poor sleep quality and stress ${ }^{[15]}$. Another researcher conducted study on quality of life and social anxiety among students ${ }^{[16]}$. Similarly another researcher found perceived stress found significantly related to sleep quality ${ }^{[17,18]}$. In a recent study found that stress and quality of life negatively associated with each other among university students ${ }^{[19]}$. On a similar line, stress and sleep are necessary elements of life and these two important factors significantly affect the academic performance of medical students ${ }^{[20]}$. Very recently, study examined the quality of life of hypertensive patients. It is influenced by several factors, like age, gender, educational background, ethnicity and nutritional status ${ }^{[21]}$. Another factor that is also very important is the quality of sleep. Recent studies have been conducted on the day time sleepiness in relation to fear of COVID-19 and emotional adjustment among adolescent ${ }^{[22]}$, perceived stress negatively affect the optimism and well-being. The outcome of perceived stress may affect the person bouncing back from adversity ${ }^{[23]}$.

\subsection{Rationale of the Study}

On the basis of literature we can find that earlier studies mainly focused on stress, optimism, wellbeing, social skills and emotional adjustment ${ }^{[5,22,23]}$ but very few studies has been conducted on the variable of day time sleepiness with quality of life so there is need to study the day time sleepiness and quality of life which predicts the perceived stress among youth.

\subsection{Objectives}

- To examine the relationship between day time sleepiness and perceived stress among youth.

- To investigate the relationship between perceived stress and quality of life among youth.

- To investigate the correlations between day time sleepiness and quality of life among youth.

- To find out the predictors of perceived stress among youth.

\subsection{Hypotheses}

- There will be a positive correlation between day time sleepiness and perceived stress among youth.

- There will be a positive relation between perceived stress and quality of life among youth.

- There will be a positive relation between day time sleepiness and quality of life among youth.

- Day time sleepiness and quality of life will be the predictor of perceived stress among youth.

\section{Method}

\subsection{Sample}

The study was conducted through online mode; the Google form was created and circulated on different WhatsApp groups and individual concern. The sample consists of 150 youth (81 Males and 69 Females). Their age ranged between 18-24 years. Data description table is as mentioned below:

\begin{tabular}{cccccc}
\hline S.No. & Male & Female & Total Sample & Occupation & Age range \\
\hline 1 & 81 & 69 & 150 & Students & 18 to 24 years \\
\hline
\end{tabular}




\subsection{Tools for the Study}

The following psychometrics tools were used for the data collection.

\subsubsection{The Epworth Sleepiness Scale (ESS) ${ }^{[24]}$}

ESS consists of eight items which measured the daytime sleepiness with the help of eight short questions. This scale is very helpful in assessing and diagnosing the sleep related problems. It was developed by Dr Murray Johns of Epworth hospital in Melbourne, Australia. The Respondents related each item on a 4-point like types scale. Answer include "no chance of dozing", slight chance of dozing", "moderate chance of dozing", high chance of dozing". The minimum score possible for each question is 0 and the maximum is 3. Higher score indicates severe day time sleepiness and lower score indicates lower day time sleepiness. ESS has appropriate reliability (Cronbach's alpha, 0.75) and validity (Convergent \& Discriminant) reported by Baumgartel, Terhorst, Conley \& Roberts in $2013^{[25]}$.

\subsubsection{World Health Organization Quality of Life- BREF (WHOQOL-BREF) ${ }^{[26]}$ :}

It is 26 items scale in which two items are related to the overall QOL and general health of the person. One question is related to a broad comprehensive assessment of QOL which is included in WHO QOL-100 scale. The is a five point rating scale. The scale reveals quality of life in terms of four significant factors like, Physical Health, Psychological Health, Social Relationship, and Environment. Cronbach's alpha values showed for each of the 4 factors which range from .66 (for domain 3 ) to .84 (for domain 1). Factors scores were scaled in positive direction (i.e., high scores indicate high quality of life). The scoring was opposite for negative items.

\subsubsection{Perceived Stress Scale (PSS) ${ }^{[27]}$}

It is ten item scale which were designed to assess the degree in which persons perceive their life as stressful. Participant answers each question on a five point Likert type scale which is range from zero (Never) to four (Very Often). High scores reveal high perceptions of stress and low scores indicate low stress. The PSS having the appropriate coefficient alphas of .84 and .85 for two college samples ${ }^{[27]}$. The PSS has been positively related with lifeevent scores, depressive and physical symptomatology, social anxiety, and maladaptive health related behaviours (e.g., increased smoking; ${ }^{28]}$ ). These significant evidence and studies reveal its construct and concurrent validity.

\subsection{Procedure}

After informed consent the proper instruction was given to participants, and then the above mentioned psychometric tools were administered through online Google form and obtained data were analysed with the help of SPSS-16 Version. The scoring of filled questionnaires has been completed with help of manual and instruction were followed which was given in the test.

\section{Results}

The present study was conducted to examine the day time sleepiness, quality of life and perceived stress among youth. The obtained data were analysis by applying descriptive statistics i.e. mean and SD, and Pearson's product Moment method of correlation. Descriptive results revealed normal day Time sleepiness (Mean=7.30, $S D=5.04$ ) from a maximum of 24 which indicate that participant tend to be less sleepy during the day therefore it is normal level of sleepiness, quality of life (Mean range from 9.32 to 23.0 , \& SD range from 4.59 to 10.52 ) from a maximum of 120, and low on perceived stress (Mean $=14.72$, $S D=8.0$ ) from a maximum of 40 (refer Table 1).

Table 1 shows the correlation between day time sleepiness and perceived stress among youth. Relationship between day time sleepiness and perceived stress was

Table 1. Inter-correlation Matrix

\begin{tabular}{|c|c|c|c|c|c|c|}
\hline & Perceived Stress & $\begin{array}{c}\text { Day Time Sleepi- } \\
\text { ness }\end{array}$ & $\begin{array}{c}\text { Physical Health } \\
\text { QOL }\end{array}$ & $\begin{array}{c}\text { Psychological Health } \\
\text { QOL }\end{array}$ & $\begin{array}{c}\text { Social Relationship } \\
\text { QOL } \\
\end{array}$ & Environment QOL \\
\hline Perceived Stress & -------- & $.56^{* *}$ & $.40 * *$ & $.52 * *$ & $.42 * *$ & $.55 * *$ \\
\hline Day Time Sleepiness & & ------------- & $.47^{* *}$ & $.49 * *$ & $.47 * *$ & $.60 * *$ \\
\hline Physical Health QOL & & & ---------- & $.70 * *$ & $.74 * *$ & $.80 * *$ \\
\hline Psychological Health QOL & & & & -------------- & $.75^{* *}$ & $.83 * *$ \\
\hline Social Relationship QOL & & & & & ----------- & $.85 * *$ \\
\hline \multicolumn{7}{|l|}{ Environment QOL } \\
\hline Mean & 14.72 & 7.30 & 22.42 & 17.15 & 9.32 & 23.01 \\
\hline S.D & 8.0 & 5.04 & 10.52 & 7.97 & 4.59 & 10.45 \\
\hline
\end{tabular}

* Correlation is significant at the 0.05 level; ** Correlation is significant at the 0.01 level 
found positive with a correlation coefficient of .56 which is significant .01 levels. Perceived stress was found to be positively correlated with quality of life with a correlation coefficient range from .40 to .55 which is significant at .01 levels. The relationship between day time sleepiness and quality of life was found to be positive with a significant correlation coefficient range from .47 to .60 $(p<.01)$.

Table 2 shows the results of stepwise regression analysis for the dependent measure perceived stress in the sample of youth. The predictor measure of day time sleepiness accounts for $31 \%$ of variance $\left(\mathrm{R}^{2}=.31\right)$ in perceived stress. $\mathrm{R}$ for day time sleepiness variable equals to .56 . The $\mathrm{F}$ value for this variable is 67.72 which is significant at .001 level of significance. It enters the equation at step one. Results reveal that day time sleepiness predicts perceived stress among youth.

Table 2. Summary of Stepwise Multiple Regression (Dependent Variable: Perceived Stress)

\begin{tabular}{|c|c|c|c|c|c|c|c|c|}
\hline Step & Variable & $\mathbf{R}$ & $\mathbf{R}^{2}$ & $\begin{array}{c}\mathbf{R}^{2} \\
\text { Change }\end{array}$ & Beta & $\begin{array}{l}\text { Std. } \\
\text { Error }\end{array}$ & F & $\mathbf{P}$ \\
\hline 1 & $\begin{array}{l}\text { Day Time Sleep- } \\
\text { iness }\end{array}$ & .56 & .31 & .31 & .56 & 6.65 & 67.72 & .001 \\
\hline 2 & $\begin{array}{l}\text { Psychological } \\
\text { Health related } \\
\text { Quality of Life }\end{array}$ & .62 & .39 & .08 & .32 & 6.28 & 18.76 & .001 \\
\hline
\end{tabular}

The next potent predictor is psychological health which enters the equation at step two, accounts for $39 \%$ of the total variance $\left(\mathrm{R}^{2}=.39\right)$ in perceived stress. $\mathrm{R}$ for this variable increases to $.62 \mathrm{~F}$ value being 18.76 which is significant at .001 level of significance. It indicates that psychological health related quality of life appropriately predicts perceive stress among youth.

\section{Discussion}

The main purpose of the current study was to explore the predictive factor of perceived stress among youth. As far as the relationships are concerned, the day time sleepiness and perceived stress positively correlated with each other. People with a high level day time sleep have high level of perceived stress. Thus hypothesis 1 stating the positive relation between day time sleepiness and perceived stress is accepted and proved here. Earlier study revealed that adolescents were observed day time sleepiness with several factors such as economic status, academic achievement, being satisfied with body image, sleeping and waking time, smoking, and reading books ${ }^{[29]}$. Other reported, adolescents have sleep problems because of the development age. This is the most commonly sleep problem that is the daytime sleepiness, which is caused by inadequate and poor quality sleep ${ }^{[30]}$.
Finding also indicated that perceived stress positively correlated with quality of life among youth. People with a high level of perceived stress report high level of problem related to the quality of life. Thus hypothesis 2 regarding the positive relation between perceived stress and quality of life is accepted and proved here. Previous study reported stress and quality of life negatively associated with each other among university students ${ }^{[19]}$. Further, stress and sleep are necessary elements of life and these two important factors significantly affect the academic performance of students ${ }^{[20]}$. Similarly, finding also indicated a positive relation between day time sleepiness and quality of life among youth which means the person with high day time sleepiness having a high level of quality of life. Thus Hypothesis 3 stating the positive relation has been proved and accepted.

Result also found that day time sleepiness and psychological health related to quality of life together accounts for $39 \%$ of variance in perceived stress among youth. So, the present study conclude that day time sleepiness and psychological health related quality of life are the potent predictors of perceived stress therefore it is playing a great role in youth's life. Youth are in the phase of very fast changing and time of uncertainty so consequently it's the age for their life development. Thus, the hypothesis 4 that stated the predictor of Perceived Stress accepted here. Current findings are in consistent with the earlier finding that showed perceived stress and health-related quality of life (HRQOL) negatively correlated with one another ${ }^{[9]}$.

\section{Conclusions}

On the basis of finding of the current study it is concluded that the quality of life and day time sleepiness have significantly related with each other. Further quality of life and perceived stress is also related factor. Thus we can say that the QOL, sleep problem and perceived stress among students are needed to be study further. So that, we can find out the more dependable result among Indian students. The article is also highlighted the need to understand the sleep related problem in connection with quality of life.

\subsection{Implications}

Findings reveal that day time sleepiness is related factors for quality of life. Therefore the study has an important implication with regard to better quality of life for youth. Study also provides the knowledge of correlated factors of perceived stress which can be the helpful for improving the quality of life for youth's population. 


\subsection{Suggestions for Future Studies}

Current study is also suggesting some future research in the areas of quality of life and day time sleepiness in connection with the youth, adolescents and adults so that more related factors can be explored.

\section{References}

[1] Delannoy, J., Mandai, O., Honoré, J., Kobayashi, T., \& Sequeira, H. (2015). Diurnal Emotional States Impact the Sleep Course. PLoS ONE, 10(11), 1-18.

[2] Heidari, H., et al. (2019). Association of Emotion Intelligence with sleep Quality. Archives of occupational Health, 3(3), 380-387.

[3] Okada, M., Otaga, M., Tsutsui, T., Tachimori, H., Kitamura, S., Higuchi, S., et al. (2018). Association of sleep with emotional and behavioral problems among abused children and adolescents admitted to residential care facilities in Japan. PLoS ONE 13(6), 1-14.

[4] Suen, L. K., Hon, K. L., \& Tam, W. W. (2008). Association between sleep behavior and sleep-related factors among university students in Hong Kong. Chronobiology International, 25(5), 760-775.

[5] Panchal, S., \& Joshi, H. L. (2014). Social skills in relation to quality of life among youths. In A. Sheema \& I. Naved (Eds.), Perspectives on Health and Well Being in India (pp. 291-295). Excel India Publishers, New Delhi.

[6] Grills-Taquechel, A. E., Littleton, H. L., \& Axsom, D. (2011). Social support, world assumptions, and exposure as predictors of anxiety and quality of life following a mass trauma. Journal of anxiety disorders, 25(4), 498-506.

[7] Ketis, Zalika., Kersnik , Janko., Eder, Ksenija ,Colarič, \& Dušan (2011). Factors Associated with Health-Related Quality of Life among University Students. Srp Arh Celok Lek, 139(3-4),197-202.

[8] Charles, Luenda., Slaven, James., Mnatsakanova,Anna., Claudia, Violanti., John, Fekedulegn, Desta., Andrew, Michael., and vila, Bryan. \& Burchfiel Cecil. (2011). Association of Perceived Stress with Sleep Duration and Sleep Quality in Police Officers. International Journal of Emergency Mental Health, 13(4), 229-241.

[9] Awadh , Ammar Ihsan., Aziz , Noorizan Abdul., Yaseen, Saramd Nabhan., Abdulameer, Shaymaa Abdalwahed., Sahib , Mohanad Naji., Qutaiba \& Omer., (2013). A comparison study of perceived stress and quality of life among Master of Pharmacy and non-pharmacy master's students. Pharmacy Education, 13(1), 22-28.

[10] Fooladia , Nasim Amiric , Roohollah Jirdehib.\& Zah- ra Mohtasham. (2014). Comparison of Depression, Anxiety, Stress and Quality of life in Drug Abusers with Normal Subjects. Procedia - Social and Behavioral Sciences 159, 712-717.

[11] Sarraf, Payam., Azizi, Sepeher., \& Ghajarzadeh, Mahsa (2014). Relationship between Sleep Quality and Quality of Life in Patients with Multiple Sclerosis. International Journal of Preventive Medicine, 5(12), 1582-1586.

[12] Bin-Mallouh , Lujain T., Gamal, M., Ali, A., Abdelrahim, M., Safwan, Khan ali, Mohammed., Al-Sanea , Mohammad M., Mmed, Kharrat., \& Alrashed, M..,(2016). Investigation of Perceived Stress and Quality of Life Assessment of pharm. D. Students at Ibn Sina National College during 2016. Journal of Applied Pharmaceutical Science, 8(3), 82-90.

[13] Rebireo, Icaro., Frieiro bruna, Prelievrna .,Cezer olivera .,Burey edurado. (2018). Stress and Quality of Life Among University Students: A Systematic Literature Review. Health Professional Education, 4(2), 70-77.

[14] Sarbeen, J. Insira., \& Jayaraj Gifrina (2017). Prevalence of stress and anxiety among college students. International Journal of Science \& Engineering Development Research, 2(4), 152-156.

[15] Almojali Al., Almalki, S.A., Alothman, A.S., Masuadi, E.M., \& Alaqeel, M. K. (2017). The prevalence and association of stress with sleep quality among medical students. Journal of Epidemiology and Global Health, 7 (3), 169-174.

[16] Jarralla, H., Omari , F., altowerci , I., \& Shaddi , K. (2017). Magnitude of Social Anxiety Disorder, and Impact on Quality of Life among Medical Students, Taif City-KSA. Journal of Clinical Psychology and Psychiatry, 7(5), 1-8.

[17] Rebello, Clevin R., Kallingappa, Prasad, B., Hegde, Preethi G. (2018). Assessment of perceived stress and association with sleep quality and attributed stressors among 1st-year medical students: A cross-sectional study from karwar, Karnataka, India. Ci Ji Yi Xue Za Zhi, 30(4), 221-226.

[18] Seo, Eun Ji., Ahn, Jeong-Ah., Hayman, Laura L., Kim, Chun-Ja. (2018). The Association Between Perceived Stress and Quality of Life in University Students: The Parallel Mediating Role of Depressive Symptoms and Health-Promoting Behaviors. Asian Nursing Research, 12(3), 190-196.

[19] Ícaro, J. S., Ribeiro, Rafael-Pereira, Ivna, V. Freire, Bruno, G. De-Oliveira, Cezar A. Casotti, \& Eduardo N. Boery (2018). Stress and Quality of Life among University Students: A Systematic Literature Review. Health Professions Education, 4(2), 70-77. 
[20] Scott, Bernadette., Modna, Yuliya., Khashchuk, Daniel., \& Duke, John (2019). The Interrelationship between Perceived Stress Level, Sleep Quality, and Academic Performance among Students of a Caribbean Medical School. Anatomy Physiology \& Biochemistry International Journal, 6(1), 555676.

[21] Mariani, D., Muzasti, Riri, A., \& Thamrin, A.(2019). The Relationship between Quality of Sleep and Quality of Life of Patients in Medan, Indonesia. Open Access Macedonian Journal of Medical Sciences, 7(11), 1794-1797.

[22] Panchal, S., \& Yadav, P. (2020). Day Time Sleepiness, Fear of COVID-19 and Emotional Adjustment among Adolescent. International Journal of Education and Psychological Research (IJEPR), 9(4) 5-8.

[23] Panchal, S., Mukerjee, S., \& Kumar, U. (2016). Optimism in Relation to Well-being, Resilience and Perceived Stress. International Journal of Education and Psychological Research (IJEPR), 5(2), 1-6.

[24] Johns, M. (1991).The Epworth sleepiness scale (ESS). https://epworthsleepinessscale.com/about-theess/.

[25] Baumgartel, K., Terhorst, L., Conley, Y., \& Roberts, J.
M. (2013). Psychometric Evaluation of the Epworth Sleepiness Scale in an Obstetric Population. Sleep Med.,14(1), 116-121.

[26] WHOQOL Group (1995). The World Health Organization Quality of Life Assessment (WHOQOL): Position paper from the world health organization. Social Science \& Medicine, 41(10), 1403-1409.

[27] Cohen, S., Kamarck, T., \& Mermelstein, R. (1983). A global measure of perceived stress. Journal of Health and Social Behaviour, 24(4), 385-396.

[28] Cohen, S., Sherrod, D. R., \& Clark, M. S. (1986). Social skills and the stress-protective role of social support. Journal of Personality and Social Psychology, 50(5), 963-973.

[29] Altan, S. S., Bektas, M., Celik, I., Gerceker, Z. O., Selekoglu, Ok, Y., Ozdemir, E. Z., \& Aricioglu, A. (2018). Factors Affecting Daytime Sleepiness in Adolescents. International Journal of Caring Sciences, 11(3), 1840-1847.

[30] Aysan, E., Karakose, S., Zaybak, A., \& Ismailoglu, E. G. (2014). Sleep Quality Among Undregraduate Students and Influencing Factors. DEUHYO ED, 7(3), 193-198. 